\title{
Rising Thyroid Cancer Incidence Proximate to a New York City-Area Nuclear Power Plant
}

\author{
Joseph Mangano, Janette Sherman \\ Radiation and Public Health Project, New York, NY, USA \\ Email: odiejoe@aol.com, toxdocjs@verizon.net
}

How to cite this paper: Mangano, J. and Sherman, J. (2017) Rising Thyroid Cancer Incidence Proximate to a New York City-Area Nuclear Power Plant. Journal of Environmental Protection, 8, 1446-1459. https://doi.org/10.4236/jep.2017.812089

Received: September 15, 2017 Accepted: November 14, 2017 Published: November 17, 2017

Copyright (c) 2017 by authors and Scientific Research Publishing Inc. This work is licensed under the Creative Commons Attribution International License (CC BY 4.0).

http://creativecommons.org/licenses/by/4.0/ (c) (i) Open Access

\begin{abstract}
Thyroid cancer incidence has risen steadily in the US for several decades. While any cause of this trend has yet to be clearly identified, most analyses have concluded that there are factors other than improved detection accounting for the increase. Since exposure to radioactive iodine is the only acknowledged root cause of thyroid cancer, a review of temporal trends in incidence since the late 1970s near the Indian Point nuclear power plant, just 23 miles from the New York City border, was conducted. Rates in the four counties closest to Indian Point, where virtually the entire population resides within 20 miles of the plant, were compared with national trends in the US. The relative ratio in the local area was 0.778 in the period 1976-1981, or 22.2 percent lower than the national rate. This ratio increased steadily, to 1.579 (57.9 percent greater than the US) by the period 2000-2004, which slightly declined to 1.515 (51.5 percent greater) in the latest period available (2010-2014). Significant increases occurred for both males and females, and in each of the four counties. Annual new cases diagnosed among residents of the four counties increased from 51 to 412 between 1976-1981 and 2010-2014. Because the two large reactors at Indian Point began operations in 1973 and 1976, and exposures to radioiodine isotopes can manifest as cancer from five years to several decades after exposure, iodine emissions from Indian Point emissions should be considered as a potential factor in these trends. More studies near Indian Point and other nuclear installations should be conducted to further explore this potential association.
\end{abstract}

\section{Keywords}

Thyroid Cancer, Radiation, Iodine, Nuclear Power, Nuclear Reactor

\section{Introduction}

Incidence of thyroid cancer has risen more rapidly since the 1970s than any oth- 
er cancer in many nations, including the US. The age-adjusted annual incidence rate increased 253 percent from 4.33 to 15.27 new cases per 100,000 persons between 1980 and 2014, according to data from cancer registries in nine US cities and states comprising about one-tenth of the national population. Approximately 57,000 Americans will be diagnosed with the condition in 2017. Large and sustained increases have been documented for both genders, all races, and all age groups [1].

For over a decade, numerous articles in the professional literature have assessed potential reasons for this trend in the US. Several have attributed the increase solely to the greater ability of diagnosing the condition, particularly relatively small thyroid cancers [2] [3] [4] [5]. However, many more reviews have concluded that at most, only a portion of the increase could be due to improved diagnosis or surveillance, and that other factors have contributed to rising US thyroid cancer incidence [6]-[18].

With no consensus on the etiology of this temporal pattern, assessments of potential causative factors are merited. Universal agreement exists on only a small number of such factors. One is the presence of certain genetic mutations [19], especially familial medullary thyroid cancer or multiple endocrine neoplasia. Another is female gender, which accounts for three-fourths of all US thyroid cancer cases. But neither of these can be considered as a root cause, but instead are outcomes of still-unknown causes [20].

The risk factor, and the only root cause, universally recognized to cause thyroid cancer is exposure to high levels of ionizing radiation [20]. Even though there may be other factors not yet recognized that increase thyroid cancer risk, ionizing radiation must be included in any analysis of temporal trends of the disease. This factor has been recognized from studies of therapeutic head and neck irradiation (discontinued by the late 1950s) [21] [22], and from exposures to the various radioactive iodine isotopes, created in atomic bomb detonations and nuclear reactor operations, principally the Chernobyl meltdown of 1986. Elevated thyroid cancer rates in populations exposed to high doses of radioiodine include survivors of the Hiroshima and Nagasaki bombs in 1945 [23] [24] [25], and residents of the Marshall Islands exposed to fallout from 20 atmospheric weapons tests in the 1950s and early 1960s [26].

However, considerable numbers of studies have been published in the literature on relatively low doses of radioiodine and resulting thyroid cancer incidence. One report on elevated cancer rates in Hiroshima survivors noted that absorbed doses were relatively low to moderate [25]. The US government, which kept measurements of I-131 in milk for many US cities [27], calculated I-131 doses from atmospheric atomic bomb test fallout among the 100 Nevada tests [28] for children in each US county [29]; although doses were well below those for Japanese bomb survivors and South Pacific residents, authors calculated that as many of 212,000 of these Americans subsequently developed thyroid cancer from fallout [30]. 
Perhaps the earliest attempt to assess thyroid cancer risk from routine operations of US nuclear power plants was contained in a study by the US. National Cancer Institute (four sites in Connecticut and Iowa). Table 1 shows that the Standard Incidence Ratio (SIR, home county rate as a proportion of the state rate) for thyroid cancer increased in each of the four areas; the total SIR for all areas rose from 0.785 to 0.950 , significant at $\mathrm{p}<0.05$ [31].

The data from Table 1 may or may not have relevance to studies of thyroid cancer near nuclear reactors. The data only cover periods prior to 1985 , and areas near only four nuclear plants are included. But the consistent patterns of increasing incidence near each plant suggest that more reviews are needed.

I-131 dose estimates from the 1979 partial meltdown at the Three Mile Island nuclear plant in Pennsylvania also presented an opportunity to assess subsequent temporal changes in thyroid cancer incidence. Local rates increased substantially, but researchers were unable to establish a correlation with exposure from the meltdown [32] [33] [34].

Nuclear power plants release a relatively small amount of the radio nuclides produced in reactors into local air and water. While only a few studies have been published on thyroid cancer trends near US nuclear power reactors, these present a logical opportunity for such reviews. Among the 99 currently operating nuclear power reactors in the US, more than half have been operational for over 40 years; several began operations 1969.

The few studies in the published literature are observational studies, cited above, which provide incidence rates near nuclear plants. Perhaps the greatest limit to these analyses is the difficulty in calculating a precise dose rate, even for iodine isotopes; government requirements to measure and report such data are modest, and (except for I-129) all radioactive iodine isotopes have short half-lives that make testing in vivo samples impossible, and testing environmental samples elusive.

A recent article made a finding unique in thyroid cancer studies, and probably in radiation studies. The report assessed presence or absence of genetic mutations in DNA and RNA of 44 thyroid cancer patients who lived near the Three

Table 1. Thyroid cancer incidence, counties closest to nuclear plants before and after reactor startup, Connecticut and Iowa, 1950-1984.

\begin{tabular}{ccccc}
\hline & Before/After & \multicolumn{2}{c}{ Standard Incidence Ratio (n) } \\
\hline Nuclear Plant & Plant Startup & $\underline{\text { Before Start }}$ & $\underline{\text { After Start }}$ & $\underline{\text { Change }}$ \\
\hline Haddam Neck CT & $1950-671968-84$ & $0.94(36)$ & $1.03(76)$ & +9 \\
Millstone CT & $1950-701971-84$ & $0.69(64)$ & $0.79(90)$ & +10 \\
Duane Arnold IA & $1969-741975-84$ & $0.92(23)$ & $1.13(77)$ & +21 \\
Ft. Calhoun IA & $1969-731974-84$ & $0.52(1)$ & $0.92(6)$ & +40 \\
TOTAL & & $0.785(124)$ & $0.950(249)$ & $+16.5 \mathrm{p}<0.05$
\end{tabular}

Rates adjusted to 1970 US standard population. Counties included are Middlesex CT (Haddam Neck), New London CT (Millstone), Benton/Linn IA (Duane Arnold), Harrison IA (Ft. Calhoun). 
Mile Island plant. Cases were those diagnosed 1984-1996 (5 to 17 years after the 1979 partial meltdown), and likely affected by iodine emissions from the meltdown. Controls were those diagnosed before 1984 or after 1996, and not affected the meltdown due to known latency between exposure and cancer manifestation. Cases had a significantly $(p=0.04)$ lower proportion of BRAFV600 Emutations, which are not associated with radiation-induced thyroid cancer. Authors conclude that the data suggest radiation released from the meltdown may have contributed to the development of thyroid cancer in some patients [35].

This recent finding suggests further study be conducted on thyroid cancer patterns near US nuclear plants. One review identified unusually elevated 2001-2005 incidence rates of the disease in a geographic area encompassing a 90-mile radius in eastern Pennsylvania, central New Jersey, and southern New York. This area is the site of 16 nuclear power reactors, 13 of which were still in operation by mid-2017; among the three that have shut down is the Three Mile Island 2 reactor where the 1979 meltdown occurred [36]. It is indeed unfortunate that geographic differences in thyroid cancer incidence have been largely ignored in the scientific literature, and a reminder that more analyses should be conducted on the still-unresolved issue of what is causing such a bold increase in thyroid cancer incidence.

Within this area is the Indian Point nuclear plant, located just 23 miles north of the New York City border. About 17.2 million persons lived within a 50-mile radius of the plant in 2010, the most near any US plant [37] Indian Point consists of one reactor that operated from 1962-1974, and two reactors still in operation that started in 1973 and 1976. The advanced age of the Indian Point reactors, the dense population proximate to the plant, and the paucity of professional journal articles on thyroid cancer near US nuclear power plants suggest a review of the Indian Point area is merited.

\section{Materials and Methods}

This review will compare temporal trends in thyroid cancer incidence in the areas closest to Indian Point to US trends. The target population selected for study includes the New York counties of Orange, Putnam, Rockland, and Westchester. Indian Point lies at the crossroads of these four counties, and virtually all its 1.78 million residents live within 20 miles of the plant, meaning that the greatest levels of fallout from routine airborne and waterborne emissions will enter bodies of these residents. The only study of in vivo radioactivity levels near US nuclear plants ever conducted measured concentrations of radioactive Strontium-90 in deciduous teeth, mostly near six nuclear plants. Of these, the highest average concentration was observed in these counties closest to Indian Point [38].

The New York State Cancer Registry makes available county-specific incidence data on various types of cancer for the years 1976 to 2014 (as of August 2017). Data are aggregated into groups of five- or six-year periods of diagnosis, 
with males and females reported separately. The Registry provides the number of cases, and the age-adjusted annual incidence rate per 100,000 persons, adjusted to the 2000 US standard population, by period, gender, and county [39]. In addition, national rates per 100,000, also adjusted to the 2000 US standard, are also available for the same periods. The five states and four metropolitan areas with the established cancer registries by the 1970s will serve as a control group. These areas include Connecticut, Hawaii, Iowa, New Mexico, Utah, Atlanta Detroit, San Francisco, and Seattle [1]. Except for Connecticut, with two nuclear plants, and Iowa with one, none of these areas are proximate to nuclear power plants.

The earliest period with available cancer data (1976-1981) represents a period just after the two Indian Point reactors began operations (1973 and 1976). It is highly likely that few, if any, 1976-1981 thyroid cancer cases were caused by emissions from these reactors, as the latency period between exposure and cancer manifestation is acknowledged to be between several years and decades. Thus, the earlier period can be considered a baseline to be compared to future years, when any radiation-related thyroid cancers near Indian Point could be expected.

The relative ratio (RR) will be calculated by comparing the local rate versus the US. For example, if the four-county rate is $15.3 \%$ below that of the five states and four counties, the RR will be 0.857 ; if the local rate were $20.1 \%$ higher, the RR would be 1.201. Trends in RR after 1976-1981 ("expected"), versus the US, will be the basis for evaluating whether subsequent trends are greater or lower than expected.

Actual rates are available for each gender in each of the four counties closest to Indian Point and the US. In addition, estimated rates will be calculated for both genders combined in each of the four counties, and for males, females, and both genders in all four counties combined. Calculations will be made by weighing rates proportionate to populations in each group. US Census Bureau annual populations, used in analyses by the US Centers for Disease Control and Prevention, are used [40]. For example, calculating a rate for males and females combined will weigh the female population (typically about $51 \%$ ) and male population (about $49 \%$ ). This estimated rate closely approximates the actual rate. For example, the age-adjusted US thyroid cancer rates for males and females for 2010-2014 are 7.1 and 21.0, respectively. The estimated rate, 14.2 (rounded to one decimal place) is equal to the actual rate of 14.2 given in official statistics [1]. The four-county estimate uses county-specific populations; the 2016 proportions accounted for by each county are given in Table 2 [41].

Statistical significance of differences between local vs. US rates is calculated by using the $95 \%$ confidence interval provided by the New York State Cancer Registry, for each period, for each gender and county.

\section{Results}

Table 3 and Figure 1 present trends in rates of thyroid cancer incidence (cases per 100,000 population, adjusted to the 2000 US standard) for males, females, 
and total, for the four-county area, for each period from 1976-1981 to 2010-2014.

Table 2. 2016 Estimated populations four counties nearest Indian point nuclear plant.

\begin{tabular}{ccc}
\hline County & 2016 Population & Proportion \\
\hline Orange & 379,210 & $21.3 \%$ \\
Putnam & 98,900 & $5.6 \%$ \\
Rockland & 326,780 & $18.4 \%$ \\
Westchester & 974,542 & $54.8 \%$ \\
TOTAL & $1,779,432$ & $100.0 \%$ \\
\hline
\end{tabular}

Table 3. Thyroid cancer incidence, both genders four New York counties vs. US by years of diagnosis, 1976-2014.

\begin{tabular}{|c|c|c|c|c|c|}
\hline \multicolumn{4}{|c|}{$\underline{4 \text { Counties }}$} & \multirow{2}{*}{$\begin{array}{l}\text { Rate } \\
\underline{\text { US }}\end{array}$} & \multirow{2}{*}{$\underline{\mathrm{RR}, \text { Local vs. US }}$} \\
\hline Year of Diagnosis & $\underline{\text { Rate }}$ & Cases & $\underline{\mathrm{CI}}$ & & \\
\hline \multicolumn{6}{|l|}{ Males } \\
\hline 1976-1981 & 2.7 & 100 & 0.6 & 2.9 & 0.945 \\
\hline 1982-1987 & 2.7 & 109 & 0.6 & 2.9 & 0.931 \\
\hline $1988-1993$ & 3.2 & 135 & 0.6 & 3.2 & 0.986 \\
\hline 1994-1999 & 4.4 & 199 & 0.7 & 3.6 & $1.222^{*}$ \\
\hline $2000-2004$ & 7.2 & 288 & 0.9 & 4.7 & $1.543^{*}$ \\
\hline 2005-2009 & 9.9 & 419 & 1.2 & 6.3 & $1.571^{*}$ \\
\hline $2010-2014$ & 12.1 & 540 & 1.3 & 7.6 & $1.592^{*}$ \\
\hline \multicolumn{6}{|l|}{$\underline{\text { Females }}$} \\
\hline $1976-1981$ & 4.6 & 208 & 0.7 & 6.6 & $0.705^{\star}$ \\
\hline $1982-1987$ & 5.4 & 253 & 0.7 & 6.9 & $0.786^{*}$ \\
\hline $1988-1993$ & 6.5 & 322 & 0.8 & 7.7 & $0.850^{*}$ \\
\hline 1994-1999 & 11.3 & 571 & 1.0 & 9.7 & $1.167^{\star}$ \\
\hline $2000-2004$ & 20.9 & 929 & 1.4 & 13.2 & $1.582^{\star}$ \\
\hline 2005-2009 & 27.1 & 1232 & 1.7 & 18.5 & $1.462^{*}$ \\
\hline $2010-2014$ & 32.7 & 1522 & 1.8 & 22.1 & $1.482^{*}$ \\
\hline \multicolumn{6}{|l|}{ All } \\
\hline $1976-1981$ & 3.7 & 308 & 0.7 & 4.8 & $0.778^{*}$ \\
\hline $1982-1987$ & 4.1 & 362 & 0.7 & 4.9 & $0.830^{*}$ \\
\hline 1988-1993 & 4.9 & 457 & 0.7 & 5.5 & 0.892 \\
\hline 1994-1999 & 7.9 & 770 & 0.9 & 6.7 & $1.186^{*}$ \\
\hline $2000-2004$ & 14.2 & 1217 & 1.2 & 9.0 & $1.579^{*}$ \\
\hline 2005-2009 & 18.7 & 1651 & 1.5 & 12.5 & $1.495^{*}$ \\
\hline 2010-2014 & 22.6 & 2062 & 1.6 & 14.9 & $1.515^{*}$ \\
\hline
\end{tabular}

*Denotes statistically significant difference, local vs. US. 


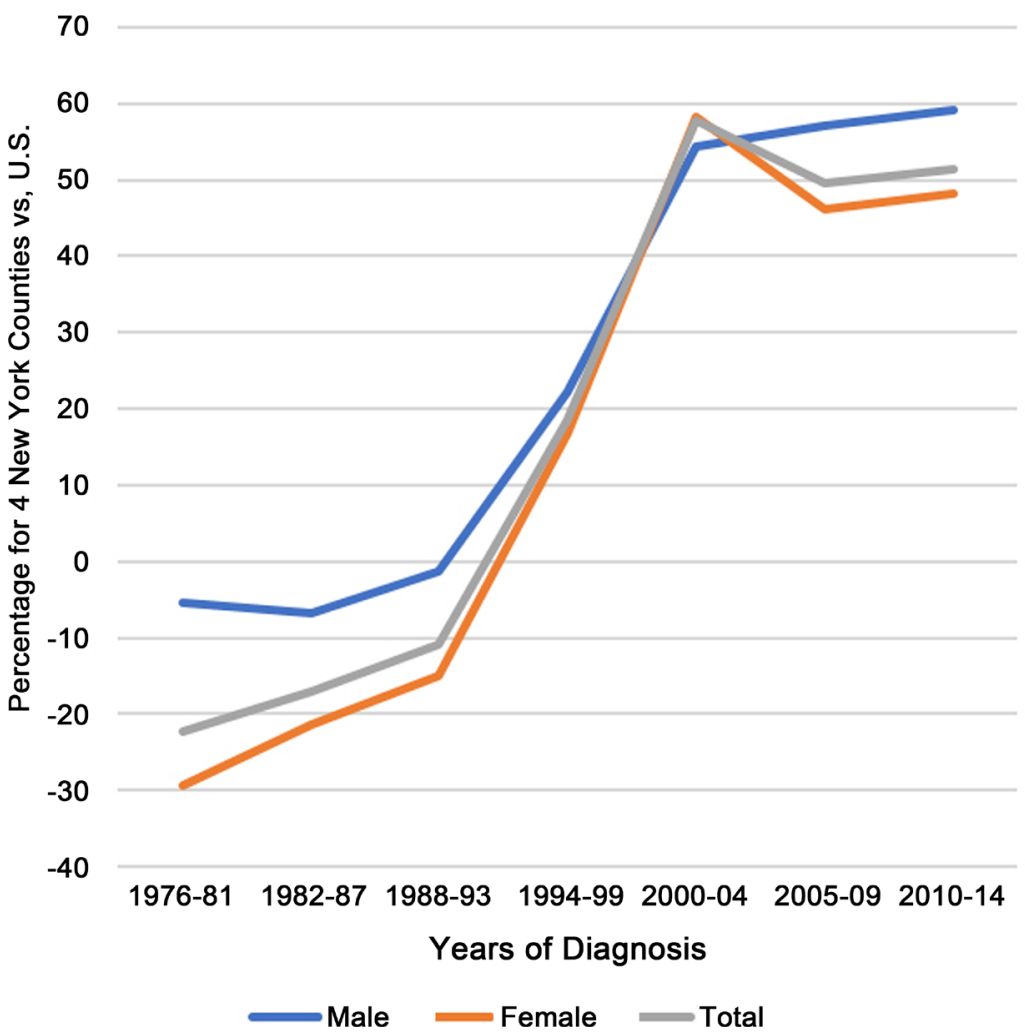

Figure 1. Thyroid cancer incidence, both genders four New York counties vs. US by years of diagnosis, 1976-2014.

During the baseline period, the RR was 0.778 , meaning the local rate was 22.2 percent less than the US rate. By 2000-2004, the RR had more than doubled, to 1.579 (local rate is 57.9 percent greater than the US). In the two latest periods, the rate dropped just slightly, an estimated 1.530 for the 15-year period 2000-2014. The annual number of cases diagnosed in residents of the four counties was 51.1 in 1976-1981, or 308 cases in six years. By 2010-2014, the number had soared to 412.4, or 2062 in five years. Females have always accounted for most cases; the female percentage of cases rose from $67.5 \%$ (208/308) in 1976-1981 to $73.8 \%(1522 / 2062)$ in 2010-2014.

Male and female trends showed steadily rising RRs in the periods after the 1976-1981 baseline to 2000-2004. (The only exception is slight the male decline from 1976-81 to 1982-1987). The RR continued to rise for males in the $21^{\text {st }}$ century, while declining slightly for females. The 15-year RR for males and females in 2000-2014 are 1.569 and 1.508, respectively. In the most recent four periods, beginning 1994, all local rates were significantly greater than the US Prior to that, rates were significantly lower for all three periods (females), and two of three periods (total).

In 1976-1981, the thyroid incidence rate in the Indian Point area was well below that of the nation. The RRs in four-county area were $0.945,0.705$, and 0.778 for males, females, and both genders (Table 3). A steady increase in RR was observed for the next four periods for males, females, and both genders, reaching 
$1.543,1.582$, and 1.579 for males, females, and both genders in 2000-2004. Thereafter, male RRs in the four counties continued to rise, while the female and total rate declined slightly; the RR for the most recent period (2010-2014) was 1.515. The largest increases in RR were observed in the late 1990s and early 2000s.

Table 4 and Figure 2 present changes in RR for each period subsequent to the 1976-1981 baseline for each of the four local counties.

Table 4. Thyroid cancer incidence, both genders four New York counties vs. US by years of diagnosis, 1976-2014.

\begin{tabular}{|c|c|c|c|c|c|}
\hline & County & & & Rate & \\
\hline Year of Diagnosis & $\underline{\text { Rate }}$ & Cases & $\underline{\mathrm{CI}}$ & $\underline{\mathrm{US}}$ & \\
\hline \multicolumn{6}{|l|}{ Orange County } \\
\hline 1976-1981 & 2.3 & 32 & 1.2 & 4.8 & $0.474^{*}$ \\
\hline 1982-1987 & 3.7 & 56 & 1.4 & 4.9 & 0.749 \\
\hline $1988-1993$ & 3.9 & 66 & 1.4 & 5.5 & $0.711^{*}$ \\
\hline 1994-1999 & 8.3 & 156 & 1.8 & 6.7 & 1.240 \\
\hline $2000-2004$ & 16.6 & 287 & 2.6 & 9.0 & $1.839^{*}$ \\
\hline $2005-2009$ & 20.3 & 376 & 2.9 & 12.5 & $1.625^{\star}$ \\
\hline 2010-2014 & 24.0 & 450 & 3.1 & 14.9 & $1.608^{*}$ \\
\hline \multicolumn{6}{|l|}{$\underline{\text { Putnam County }}$} \\
\hline $1976-1981$ & 4.0 & 16 & 2.6 & 4.8 & 0.844 \\
\hline 1982-1987 & 2.3 & 10 & 2.1 & 4.9 & $0.466^{*}$ \\
\hline $1988-1993$ & 3.8 & 19 & 2.4 & 5.5 & 0.694 \\
\hline 1994-1999 & 6.9 & 37 & 3.3 & 6.7 & 1.034 \\
\hline $2000-2004$ & 15.1 & 76 & 4.9 & 9.0 & $1.676^{*}$ \\
\hline 2005-2009 & 20.9 & 114 & 5.5 & 12.5 & $1.667^{*}$ \\
\hline 2010-2014 & 26.1 & 139 & 6.2 & 14.9 & $1.751^{*}$ \\
\hline \multicolumn{6}{|l|}{$\underline{\text { Rockland County }}$} \\
\hline $1976-1981$ & 4.8 & 64 & 1.7 & 4.8 & 1.003 \\
\hline $1982-1987$ & 5.5 & 82 & 1.7 & 4.9 & 1.116 \\
\hline 1988-1993 & 7.8 & 125 & 1.9 & 5.5 & $1.415^{*}$ \\
\hline 1994-1999 & 9.5 & 158 & 2.1 & 6.7 & $1.416^{*}$ \\
\hline $2000-2004$ & 18.2 & 267 & 3.0 & 9.0 & $2.017^{*}$ \\
\hline 2005-2009 & 19.0 & 284 & 3.1 & 12.5 & $1.514^{\star}$ \\
\hline $2010-2014$ & 23.4 & 374 & 3.4 & 14.9 & $1.568^{*}$ \\
\hline \multicolumn{6}{|l|}{ Westchester County } \\
\hline $1976-1981$ & 3.8 & 196 & 0.8 & 4.8 & $0.796^{*}$ \\
\hline $1982-1987$ & 4.0 & 214 & 0.8 & 4.9 & $0.803^{*}$ \\
\hline $1988-1993$ & 4.5 & 247 & 0.8 & 5.5 & $0.815^{*}$ \\
\hline 1994-1999 & 7.4 & 418 & 1.0 & 6.7 & 1.111 \\
\hline $2000-2004$ & 12.0 & 587 & 1.3 & 9.0 & $1.335^{*}$ \\
\hline 2005-2009 & 17.8 & 877 & 1.7 & 12.5 & $1.419^{*}$ \\
\hline 2010-2014 & 21.4 & 1099 & 1.8 & 14.9 & $1.436^{*}$ \\
\hline
\end{tabular}

${ }^{\star}$ Denotes statistically significant difference, local vs. US. 


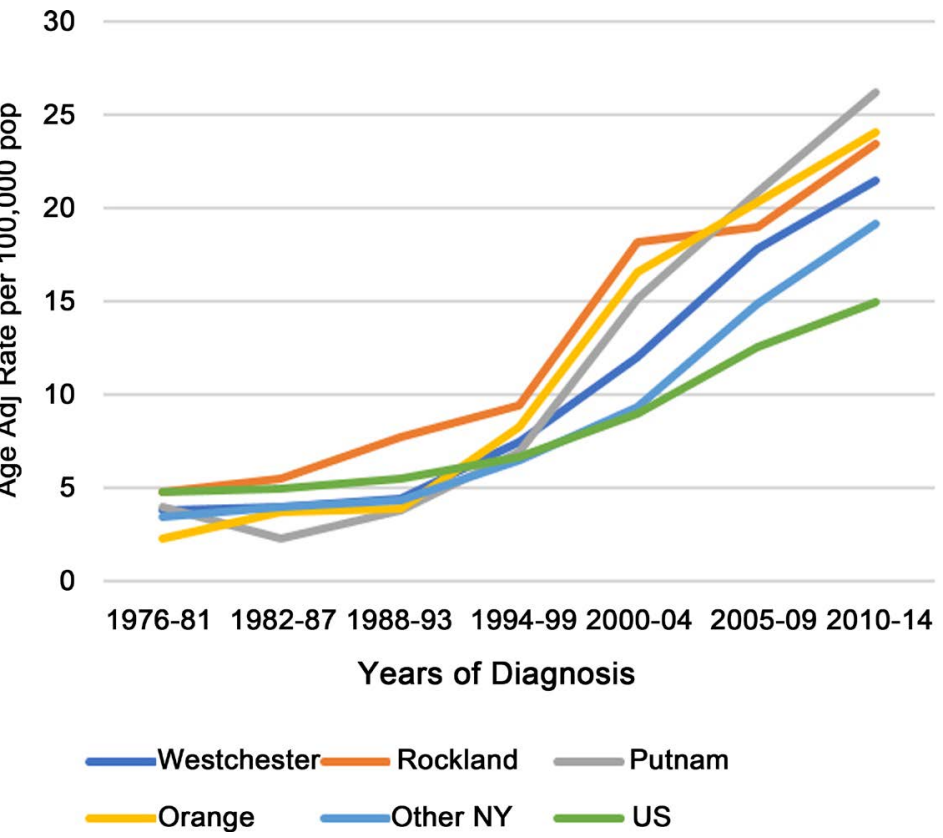

Figure 2. Thyroid cancer incidence, both genders each of 4 NY counties vs. other NY and us by years of diagnosis, 1976-2014.

In the baseline period, the RR for each county was less than 1.000 (county rate below the US), except for Rockland County, which was essentially equal to the nation at 1.003. Aside from the 1982-1987 decline in Putnam County (a small county with only 10 reported cases in that period), all counties reported consistently higher RRs until 2000-2004. After 2004, RRs in Putnam and Westchester Counties continued to rise, while those in Orange and Rockland declined somewhat. The 15-year RRs for Orange, Putnam, Rockland, and Westchester Counties in 2000-2014 were 1.691, 1.698, 1.700, and 1.397, respectively-essentially identical except for Westchester County.

For each county, in each of the three latest five-year periods, the local rate was significantly greater than the US (each of the last five periods in Rockland County). Rates were significantly lower prior to 1994 in Orange County ( 2 of 3 periods), Putnam County ( 1 of 3 periods), Rockland County ( 0 of 3 periods), and Westchester County ( 3 of 3 periods).

\section{Discussion}

We have observed a steady rise in thyroid cancer incidence RR in the four counties within 20 miles of the Indian Point nuclear power installation from 1976-1981 until the present. While the US rate has steadily increased, the rate of increase in the local area is far greater. Because the RR doubled, rising from 0.778 to 1.530 from 1976-1981 to 2000-2014, thyroid cancer incidence in the local counties has transformed from significantly less than to significantly greater than the US. The increase has been consistent for both genders and all four counties. Annual reported cases have risen from 51 to 412 from 1976-1981 to 2010-2014. 
Improved diagnostic efforts are very likely not the sole cause of the rapid increase in US thyroid cancer rates in the past several decades, as most reviews discussed earlier in this report have concluded. The only nation with a screening program for the disease is South Korea, starting in 1999; the rate of thyroid cancer in that nation soared from 5 to 70 cases per 100,000 persons between 1993 and 2011 [42], far greater than that of the US (age-adjusted rate from 5.64 to 14.87) [1] or other nations with established cancer registries. In the case of the steadily elevated RRs in the four county-area studied, there is no evidence that improvements in case detection have improved more than in the US.

The paucity of known causes of thyroid cancer, in addition to the presence of two large nuclear power reactors at Indian Point beginning 1973 and 1976, raises the question of whether radioactive iodine emissions from these reactors have contributed to the trend. Official statistics documenting such emissions which are not comprehensive; however, annual airborne emissions of iodine-131 and particulates from Indian Point rank $5^{\text {th }}$ highest among all 72 US nuclear power plants (Table 5). The 17.46 curies place Indian Point ahead of the 1979 meltdown at Three Mile Island (14.20) [43].

These data, the known latency between exposure and manifestation of thyroid cancer of five years to several decades, and the recent finding that thyroid cancer near the Three Mile Island nuclear plant after its partial meltdown is linked with an unusually high proportion of cases with mutations associated with thyroid cancer [19], suggest that Indian Point may be one cause of elevated local thyroid cancer rates, and that further analysis is merited. The data do not represent conclusive proof of a cause-and-effect association, but are a reminder of the need to conduct more studies addressing the issue of potential spatial relations between environmental iodine and local risk of thyroid cancer.

US thyroid cancer increases are not limited to the Indian Point area. We observed that thyroid is the fastest-rising malignancy in the nation, beginning about 1980-when a large expansion of nuclear power reactors and their electrical production were ongoing, given in Table 6 [44]. Any further review of thyroid cancer trends should include consideration of potential risk from iodine emitted from reactors across the US.

We recommend that future analyses be conducted. More detailed review of any demographic changes in the local area near Indian Point in the past four

Table 5. Highest airborne releases, iodine-131 and particulates, in curies of 72 total US nuclear power plants, 1970-1987.

\begin{tabular}{ccc}
\hline$\underline{\text { Plant }}$ & $\underline{\text { State }}$ & $\underline{\text { Curies }}$ \\
\hline Dresden & IL & 95.58 \\
Oyster Creek & NJ & 76.80 \\
Millstone & CT & 32.64 \\
Quad Cities & IL & 26.79 \\
Indian Point & NY & 17.46 \\
\hline
\end{tabular}


Table 6. Nuclear reactors and electricity generation, united states in five-year intervals, 1975 to 2015.

\begin{tabular}{lcc}
\hline Year & Reactors & Electricity \\
\hline 1975 & 57 & 172.5 \\
1980 & 71 & 251.1 \\
1985 & 96 & 383.7 \\
1990 & 112 & 576.9 \\
1995 & 109 & 673.4 \\
2000 & 104 & 753.9 \\
2005 & 104 & 782.0 \\
2010 & 104 & 807.0 \\
2015 & 99 & 797.2 \\
\hline
\end{tabular}

Electricity measured as net generation in millions of kilowatt-hours.

decades should be compared with those of the US Analysis in incidence changes of other cancers should be conducted-in particular, those most strongly linked with radiation, such as childhood cancer. Studies like this one can also be duplicated near other US nuclear plants, as all states now maintain established cancer registries. Finally, more studies identifying the proportion of cancers with radiation-specific genetic mutations are critical, since precise estimates of dose remain elusive.

\section{References}

[1] Howlader, N., Noone, A.M., Krapcho. M., et al. (2017) SEER Cancer Statistics Review, 1975-2014. National Cancer Institute, Bethesda, MD.

https://seer.cancer.gov/csr/1975_2014

[2] Davies, L. and Welch, H.G. (2006) Increasing Incidence of Thyroid Cancer in the United States, 1973-2002. JAMA, 295, 2164-2167. https://doi.org/10.1001/jama.295.18.2164

[3] Udelman, R. and Zhang, Y. (2014) The Epidemic of Thyroid Cancer in the United States: The Role of Endocrinologists and Ultrasounds. Thyroid, 24, 472-479. https://doi.org/10.1089/thy.2013.0257

[4] O’Grady, T.J., Gates, M.A. and Boscoe, F.P. (2015) Thyroid Cancer Incidence Attributable to Overdiagnosis in the United States, 1981-2011. International Journal of Cancer, 137, 2664-2673. https://doi.org/10.1089/thy.2013.0257

[5] Altekruse, S., Das, A., Cho, H., Petkov, V. and Yu, M. (2015) Do Thyroid Cancer Incidence Rates Increase with Socioeconomic Status among People with Health Insurance? An Observational Study Using SEER Population-Based Data. BMJ Open, 5, Article ID: e009846. https://doi.org/10.1089/thy.2013.0257

[6] Chen, A.Y., Jemal, A. and Ward, E.M. (2009) Increasing Incidence of Differentiated Thyroid Cancer in the United States, 1988-2005. Cancer, 115, 3801-3807. https://doi.org/10.1002/cncr.24416

[7] Enewold, L., Zhu, K., Ron, E., Marrogi, A.J., Stojadinovic, A., Peoples, G.E. and Devesa, S.S. (2009) Rising Thyroid Cancer Incidence in the United States by Demographic and Tumor Characteristics, 1980-2005. Cancer Epidemiol Biomarkers Prevention, 18, 784-791. https://doi.org/10.1158/1055-9965.EPI-08-0960 
[8] Cramer, J.D., Fu, P., Harth, K.C., Margevicius, S. and Wilhelm, L.N. (2010) Analysis of the Rising Incidence of Thyroid Cancer Using the Surveillance, Epidemiology and End Results National Cancer Data Registry. Surgery, 148, 1147-1152. https://doi.org/10.1016/j.surg.2010.10.016

[9] Yu, G.P., Li, J.C. and Branovan, D. (2010) Thyroid Cancer Incidence and Survival in the National Cancer Institute Surveillance, Epidemiology, and End Results Race/Ethnicity Groups. Thyroid, 20, 465-473. https://doi.org/10.1016/j.surg.2010.10.016

[10] Aschebrook-Kilfoy, B., Ward, M.H., Sabra M.M. and Devesa S.S. (2011) Thyroid Cancer Incidence Patterns in the United States by Histologic Type, 1992-2006. Thyroid, 21, 125-134. https://doi.org/10.1089/thy.2010.0021

[11] Enewold, L.R., Zhou, J., Devesa, S.S., Berrington de Gonzalez, A., Anderson, W.F., Zahm, S.H., Stojadinovic, A., Peoples, A., Peoples, G.E., Marrogi, A.J., Potter, J.F., McGlynn, K.A. and Zhu, K. (2011) Thyroid Cancer Incidence among Active Duty U.S. Military Personnel, 1990-2004. Cancer Epidemiology, Biomarkers \& Prevention, 20, 2369-2376. https://doi.org/10.1158/1055-9965.EPI-11-0596

[12] Holman, D.M., Soman, A., Watson, M., Weir, H.K., Trivers, K.F. and White, M.C. (2011) Examination of the Increase in Thyroid Cancer Incidence among Younger Women in the United States by Age, Race, Geography, and Tumor Size, 1999-2007. Journal of Adolescent and Young Adult Oncology, 1, 95-102. https://doi.org/10.1089/jayao.2011.0014

[13] Holmes, L., Hossan, J. and Opara, F. (2012) Pediatric Thyroid Carcinoma Incidence and Temporal Trends in the USA (1973-2007): Race or Shifting Diagnostic Paradigm? International Scholarly Research Notices. Oncology, 2012, Article ID: 907197. https://doi.org/10.5402/2012/906197

[14] Simard, E.P., Ward, E.M., Siegel, R. and Jemal, A. (2012) Cancers with Increasing Incidence Trends in the United States: 1999 through 2008. Cancer Journal for Clinicians, 62, 118-128. https://doi.org/10.3322/caac.20141

[15] Aschebrook-Kilfoy, B., Grogan, R.H., Ward, M.H., Kaplan, E. and Devesa, S. (2013) Follicular Thyroid Cancer Incidence Patterns in the United States, 1980-2009. Thyroid, 23, 1015-1021. https://doi.org/10.1089/thy.2012.0356

[16] Li, N., Du, X.L., Reitzel, L.R., Xu, L. and Sturgis, E.M. (2013) Impact of Enhanced Detection on the Increase in Thyroid Cancer Incidence in the United States: Review of Incidence Trends by Socioeconomic Status within the Surveillance, Epidemiology, and End Results Registry, 1980-2008. Thyroid, 23, 103-110.

https://doi.org/10.1089/thy.2012.0392

[17] Veiga, L.H., Neta, G., Aschebrook-Kilfoy, B., Ron, E. and Devesa, S.S. (2013) Thyroid Cancer Incidence Patterns in Sao Paulo, Brazil, and the U.S. SEER Program, 1997-2008. Thyroid, 23, 748-757. https://doi.org/10.1089/thy.2012.0532

[18] Siegel, D.A., King, J., Tai, E., Buchanan, N., Ajani, U.A. and Li, J. (2014) Cancer Incidence Rates and Trends among Children and Adolescents in the United States, 2001-2009. Pediatrics, 134, e945-e955. https://doi.org/10.1542/peds.2013-3926

[19] American Cancer Society (2016) What Causes Thyroid Cancer? https://www.cancer.org/cancer/thyroid-cancer/causes-risks-prevention/what-causes .html

[20] Mayo Clinic (2017) Thyroid Cancer: Causes. Mayo Clinic, Minneapolis. http://www.mayoclinic.org/diseases-conditions/thyroid-cancer/symptoms-causes/d $\underline{\mathrm{xc}-20315673}$

[21] Pottern, L.M., Stone, B.J., Day, N.E., Pickle, L.W. and Fraumeni, J.F. (1980) Thyroid Cancer in Connecticut, 1935-1975: An Analysis by Cell Type. American Journal of 
Epidemiology, 112, 764-774. https://doi.org/10.1093/oxfordjournals.aje.a113049

[22] Zheng, T., Holford, T.R., Chen, Y., Ma, J.Z., Flannery, J., Liu, W., Russi, M. and Boyle, P. (1996) Time Trend and Age-Period-Cohort Effect on Incidence of Thyroid Cancer in Connecticut, 1935-1992. International Journal of Cancer, 67, 504-509. https://doi.org/10.1002/(SICI)1097-0215(19960807)67:4<504::AID-IJC7>3.0.CO;2-W

[23] Furukawa, K., Preston, D., Funamoto, S., Yonehara, S., Ito, M., Tokuoka, S., Sugiyama, H., Soda, M., Ozasa, K. and Mabuchi, K. (2013) Long-Term Trend of Thyroid Cancer Risk among Japanese Atomic-Bomb Survivors: 60 Years after Exposure. International Journal of Cancer, 132, 1222-1226. https://doi.org/10.1002/ijc.27749

[24] Hayashi, Y., Lagarde, F., Tsuda, N., Funamoto, S., Preston, D.L., Koyama, K., Mabuchi, K., Ron, E., Kodama, K. and Toduoka, S. (2010) Papillary Microcarcinoma of the Thyroid among Atomic Bomb Survivors: Tumor Characteristics and Radiation Risk. Cancer, 116, 1646-1655. https://doi.org/10.1002/cncr.24872

[25] Yoshimoto, Y., Ezaki, H., Etoh, R., Hiraoka, T. and Akiba, S. (1995) Prevalence Rate of Thyroid Diseases among Autopsy Cases of the Atomic Bomb Survivors in Hiroshima, 1951-1985. Radiation Research, 141, 278-286. https://doi.org/10.2307/3579004

[26] Land, C.D., Bouville, A., Apostoaei, I. and Simon, S.L. (2010) Projected Lifetime Cancer Risks from Exposure to Regional Radioactive Fallout in the Marshall Islands. Health Physics, 99, 201-215. https://doi.org/10.1097/HP.0b013e3181dc4e84

[27] Campbell, J.E. and Murthy, G.K. (1963) Summary of Results from the Raw Milk Sampling Program, June 1957-April 1963. Radiological Health Data. U.S. Public Health Service, 511-519.

[28] Cochran, T.B. and Norris, R.S. (1994) United States Nuclear Tests, July 1945 to December 1992. Natural Resources Defense Council, Washington DC.

[29] National Cancer Institute (1997) Estimated Exposures and Thyroid Doses Received by the American People from Iodine 131 in Fallout Following Nevada Atmospheric Nuclear Bomb Tests. A Report from the National Cancer Institute. U.S. Department of Health and Human Services, Bethesda.

[30] Institute of Medicine and National Research Council (1998) Exposure of the American People to Iodine-131 from Nevada Atomic Bomb Tests: Review of the National Cancer Institute Report and Public Health Implications. National Academy of Sciences, Washington DC.

[31] Jablon, S., Hrubec, Z., Boice, J.D. and Stone, B.J. (1990) Cancer in Populations Living Near Nuclear Facilities. National Cancer Institute, NIH Pub. No. 90-874. U.S. Government Printing Office, Washington DC.

[32] Levin, R.J. (2008) Incidence of Thyroid Cancer in Residents Surrounding the Three Mile Island Nuclear Facility. Laryngoscope, 118, 618-628. https://doi.org/10.1097/MLG.0b013e3181613ad2

[33] Levin, R.J., DeSimone, N.F., Slotkin, J.F. and Henson, B.L. (2013) Incidence of Thyroid Cancer Surrounding Three Mile Island Nuclear Facility: The 30-Year Follow-Up. Laryngoscope, 123, 2064-2071. https://doi.org/10.1002/lary.23953

[34] Goyal, N., Camacho, F., Mangano, J. and Goldenberg, D. (2015) Evaluating for a Geospatial Relationship between Radon Levels and Thyroid Cancer in Pennsylvania. Laryngoscope, 125, E45-E49.

[35] Goldenberg, D., Russo, M., Houser, K., Crist, H., Derr, F.B., Walter, V., Warrick, J.I., Sheldon, K.E., Broach, J. and Bann, D.V. (2017) Altered Molecular Profile in Thyroid Cancers from Patients Affected by the Three Mile Island Nuclear Accident. Laryngoscope, 127, S1-S9. https://doi.org/10.1002/lary.26687 
[36] Mangano, J.J. (2009) Geographic Variation in U.S. Thyroid Cancer Incidence and a Cluster near Nuclear Reactors in New Jersey, New York, and Pennsylvania. International Journal of Health Services, 39, 643-661. https://doi.org/10.2190/HS.39.4.c

[37] Dedman, B. (2011) Nuclear Neighbors: Population Rises Near US Reactors. NBC News, April 14, 2011.

http://www.nbcnews.com/id/42555888/ns/us_news-life/t/nuclear-neighbors-popula tion-rises-near-us-reactors/\#.WYKLJr4gOM8

[38] Mangano, J.J., Gould, J.M., Sternglass, E.J., Sherman, J.D. and McDonnell, W. (2003) An Unexpected Rise of Strontium-90 in U.S. Deciduous Teeth in the 1990s. Science of the Total Environment, 317, 37-51.

[39] New York State Cancer Registry (NYSCR) (2017) Cancer Trend for New York State Counties. https://www.health.ny.gov/statistics/cancer/registry/vol3.htm

[40] U.S. Centers for Disease Control and Prevention. Compressed Mortality File: Underlying Cause of Death. https://wonder.cdc.govmortSQL.html

[41] U.S. Census Bureau. Population and Housing Unit Estimates. https://www.census.gov/program-surveys/popest/data/tables.2016.html

[42] Lin, J.S., Aiello Bowles, E.J. and Williams, S.B. (2017) Screening for Thyroid Cancer: Updated Evidence Report and Systematic Review for the U.S. Preventive Services Task Force. JAMA, 317, 1888-1903. https://doi.org/10.1001/jama.2017.0562

[43] Tichler, J., Doty, K. and Lucadamo, K. (1987) Radioactive Materials Released from Nuclear Power Plants: Annual Reports, 1970-1987. NUREG/CR-2907. Brookhaven National Laboratory, Upton.

[44] U.S. Energy Information Administration. Monthly Energy Reviews, September 2017. https://www.eia.gov/totalenergy/data/monthly/pdf/sec8_3.pdf 